\title{
Carbon C14-labeled Carboplatin
}

National Cancer Institute

\section{Source}

National Cancer Institute. Carbon C14-labeled Carboplatin. NCI Thesaurus. Code

C119702.

A radioconjug ate composed of the platinum compound carboplatin conjug ated to the isotope carbon C 14 (14C-carboplatin), which can potentially be used to predict chemoresistance to carboplatin using accelerator mass spectrometry (AMS). Upon administration of a microdose of 14C-carboplatin, the carboplatin moiety covalently binds to DNA and forms carboplatin-DNA monoadducts. Using AMS, the 14Ccarboplatin-DNA monoadducts can be detected and measured. The levels of microdoseinduced carboplatin-DNA monoadducts can be used to assess the degree of chemoresistance to carboplatin and can predict cancer response to carboplatin-based chemotherapy. The carboplatin microdose is defined as 1/100 of the pharmacologically effective concentration of carboplatin. Low levels of carboplatin monoadduct formation and increased DNA repair, measured by a decrease in the detection of carboplatin-DNA monoadducts over a given time period, are correlated with increased resistance to platinum-based chemotherapeutics. 